Article

\title{
Applying Blockchain Technology: Evidence from Norwegian Companies
}

\author{
Anne H. Gausdal ${ }^{1, *(1)}$, Karen V. Czachorowski ${ }^{1}$ (D) and Marina Z. Solesvik ${ }^{2,3}$ ([) \\ 1 Department of Maritime Operations, Faculty of Technology, Natural Sciences and Maritime Sciences, \\ University of South-Eastern Norway, Postbox 235, 3603 Kongsberg, Norway; karenvcz@gmail.com \\ 2 Nord University Business School, Nord University, Universitetsaleen, 8049 Bodø, Norway; \\ marina.solesvik@hvl.no \\ 3 Faculty of Business Administration and Social Sciences, Western Norway University of Applied Sciences, \\ Campus Haugesund, Bjørnsonsgate 45, 5528 Haugesund, Norway \\ * Correspondence: ang@usn.no; Tel.: +47-480-699-98
}

Received: 30 April 2018; Accepted: 7 June 2018; Published: 13 June 2018

\begin{abstract}
The aim of this study is to develop a theoretical framework for blockchain, operations in particular. Furthermore, we aim to identify the main drivers and barriers of digital innovation and explore the general possibilities of blockchain applications within the maritime industry. A case study approach is applied: the Norwegian offshore industry. Primary data is collected through interviews, while secondary data is collected from industrial and company reports, the Internet, and national and international media reports. We have discovered that cost reduction intentions, the high level of regulation in the maritime industry, and the large amount of data that maritime companies should process, along with the intention to work more effectively, are the main drivers of digital innovation. On the other hand, the high cost of implementation, the bad quality of Internet connections offshore, the old age of decision-makers, the technology-oriented culture, the lack of investment initiatives, the low level of blockchain diffusion through the supply chain, and risk aversion are the main barriers. The results of the qualitative study show that some of the barriers and motives of digital innovation and the introduction to blockchain technology were pointed out by earlier studies. However, we have identified several unique drivers and barriers specific to the industry. Finally, the blockchain process framework is developed.
\end{abstract}

Keywords: blockchain technology; innovation; maritime industry; supply chain; technology applied to maritime industry

\section{Introduction}

The blockchain technology (hereafter called blockchain) is presently broadening borders and expectations due to its characteristics of immutability, decentralization, and time-stamped record keeping [1]. Blockchain may have much potential in appropriate areas for adoption within many industries. This technology, which was initially created to support the Bitcoin cryptocurrency, is a distributed ledger that may be anonymous and permission-less. It is a time-stamped tampering-proof ledger that may disable intermediaries and eliminate businesses frictions that disrupt innovation adoption [2]. Blockchain is a new topic for literature, and is still unknown to the majority of industries. A recently published systematic review of blockchain literature has only identified 41 relevant studies outside of Bitcoin - all of which were published after 2012-mostly originating from the United States (US), Germany, and Switzerland [3]. Therefore, more studies related to blockchain applications are needed. 
The maritime industry is part of a complex and information-intensive maritime supply chain comprising a set of organizations that are globally connected and distributed, including other critical infrastructures that support world trade, such as transport and port structures. Although the maritime industry is technologically advanced, innovations in the maritime sector have been primarily related to ship construction, oil and gas exploration, seabed exploitation technologies, and other-mainly engineering-based-innovations. The industry lacks innovations related to operations procedures and logistics, which represent both a challenge and an opportunity. One of the most promising areas of maritime innovation is related to digitalization, including the development of smart ships, a smart fleet, and smart global logistics [4]. Big data has been the focus of shipping digitalization. Poor information management leads to increased expenses and can account for up to $20 \%$ of an operational budget [5]. A typical supply chain is expected to manage about 35 zeta bytes by 2020 [6], which is a considerable increase when compared with the average of 100 gigabytes per day of data inflow, which was recorded by a retailer supply chain management firm in 2008 [7]. Although some early adopters of blockchain already exist within the maritime industry, no academic studies of its application have been identified so far within this industry.

It is important to identify the main drivers of innovation in the maritime industry. Surprisingly, one of the most influential drivers of innovations is associated with the extant external regulations of the industry by international organizations [8]. Externally driven by these regulations, the maritime industry has shown a keen interest in pursuing eco-friendly goals, such as attempting to develop "green" technologies and a "green" supply chain. Blockchain can support regulatory bodies by enabling them to issue necessary certificates in electronic form secured by a unique blockchain-locked code that is impossible to counterfeit [9]. This has resulted in a race towards unmanned vessels, big data, artificial intelligence, and the Internet of Things (IoT) [10,11]. Other drivers of innovation are related to the need to save costs, explore new business opportunities (such as the oil and gas boom in the 1970s), and to increase safety and security with respect to piracy and cybercrimes. The latter is progressively becoming more important as the industry escalates its connection to cyber networks. Risk assessments of cyber security provide a whole path analysis rather than a smart way of finding the most vulnerable points, thus creating duplicate work and adding unnecessary costs to the process [12].

The motivation for this study is to contribute to the literature on innovation and blockchain, as well as to cover the gap in the knowledge base related to non-engineering innovations within the maritime industry [4]. The aim is manifold. First, and foremost, the aim is to develop a theoretical framework for blockchain operations: the blockchain process framework. Furthermore, we aim to clarify the possibilities and barriers of blockchain implementation, while exploring the influence of blockchain on interfirm collaboration. Finally, we intend to identify the main drivers and barriers of innovation within the maritime industry and explore the possibilities of blockchain applications in this industry. The research questions are:

1. Which general industry operations may benefit from applying blockchain technology?

2. What are the main drivers (and barriers) of digital innovation within the maritime industry?

3. What areas of the maritime industry may benefit from implementing blockchain technology?

A literature review as well as a case study provides insights that allow us to answer these questions. The Norwegian offshore industry has been selected as case study, because Norway is a high-cost country and a top maritime and offshore nation. This industry is highly innovative in technical and engineering terms, and it needs cost reduction to stay competitive. Furthermore, the Norwegian government is concerned with the development of engineering, digital, and green innovation in the industry, and provides research and development (R\&D) support through generous national research programs.

It is important to understand innovation itself, i.e., its costs and applications in the industry, how mature it is and so on, in order to devise a more structured plan for its application. Tidd, Bessant, and Pavitt [13] describe the 4Ps of innovation space as the four broad categories of innovation forms, 
which are the Product, Process, Position, and Paradigm innovation. While 'Product' deals with the changes in products/services offered by a company, 'Process' is related to the changes in how they are created and delivered. Meanwhile, 'Position' deals with changes in the products/services context, and 'Paradigm' innovation addresses changes in mental modes framing the organization's activities. The blockchain application in Tidd et al.'s [13] terms can be classified as radical at both component and system levels, since it proposes something new to the world, a new technology and a new application that impacts the whole industry and its supply chain. Supply chain innovation is a change within the supply chain network, process, technology, or a combination of these, enhancing new value creation for the stakeholders [14]. It is a fundamental instrument for enhancing supply chain performance, providing companies with several benefits, including the improvement of customer response times, lower inventory levels, better decision-making processes, and enabling visibility throughout the whole chain $[15,16]$. The blockchain application in this industry may therefore hold all the 4Ps of innovation forms, and a great cultural change would be needed in order to allow such changes [4].

Nevertheless, not all innovations are equally fitting for the whole industry, as not everything that might solve one company's problems or challenges will do the same for all of the others. Companies should exploit innovation where it fits best, instead of applying the same throughout the whole industry [17]. Additionally, technical innovations create uncertainty within potential adopters due to their expected or unexpected consequences; nonetheless, they may also represent an opportunity for reduced uncertainty, due to the information base of the technology [18]. Therefore, when evaluating which kind of innovation is right for a given industry, it is necessary to analyze each part of the industry in-depth and separately in order to grasp the new possibilities; these parts include the company's size, goals, vision, financial capacity, and its interests regarding the specific innovation in question.

Seaborne transport, together with the supporting industries, is a well-established business. Maritime transport provides low price transportation services compared to airborne, railroad, or automobile transport. However, the maritime business has some challenges; one of them is shipping cycles [19]. The competition in the industry is high, and shipping companies tend to decrease their costs in order to win the competition game and to survive in turbulent times related to shipping cycles. Political risks are also high. The changes in the industry are also stipulated by stricter environmental requirements approved by the International Maritime Organization, the European Union, and other international organizations [20,21].

Regarding digital transformation, various segments within the maritime industry seem to be at different levels of diffusion. The cruise industry is identified as visibly ahead of the others, while the situation for the cargo segment is mixed, being mostly advanced onshore [22]. Shipping companies have utilized data-driven technologies for a long time [23]. Recently, Maersk has begun a joint venture with IBM, intending to create a blockchain-based platform to connect the shipping supply chain, and to promote an open industry platform through IBM to benefit all of the parts of the ecosystem. In its initial phase, the partnership created and implemented a blockchain-based Bill of Lading, which showed an administrative cost reduction to as high as $15 \%$ of the shipped goods' value in early tests. This is an admirable saving figure, given that the total trade represents about $60 \%$ of the world's GDP [24]. Radio Frequency Identification systems are united through the IoT to generate data-based benefits for the logistics network. The Global Positions System (GPS) labeling of shipping containers to support the handling of their movement through transportation hubs is another modern IoT utilization [10]. Digital transformations have also commenced in ports: for instance, the Port of Hamburg requires all parties to connect to a shared data system [10], while the Maritime and Port Authority of Singapore have launched the Smart Port Challenge 2017 to add value to the maritime logistics chain, in collaboration with the Port of Rotterdam [25]. The concept of digital oil fields, which are constantly collecting data, has also been launched [26].

Blockchain is defined as "a shared, distributed ledger that facilitates the process of recording transactions and tracking assets in a business network. An asset can be tangible-a house, a car, cash, land—or intangible like intellectual property, such as patents, copyrights, or branding" ([27], p. 5). 
Blockchain was created in 2008 by Satoshi Nakamoto. It is basically a sequence linking a number of digital signatures, confirmed by a timestamp server [1]. The blockchain network architecture allows its participants (nodes) to share a ledger updated through peer-to-peer replication when a new transaction occurs. These replications mean that each node acts as both a publisher and a subscriber of the ledger, which are allowed to send or receive transactions to and from other nodes, while the data is synchronized across the network as the transactions occur [27]. The timestamp server, the ledger distribution, and the proof-of-work concept constitute the consensus model, which is blockchain's validation system [1], assuring that all of the transactions are authenticated, secure, and verifiable [27]. Due to its characteristics, a blockchain network allows trust within the chain for all of the users.

Other consensus models were developed after Nakamoto's initial design in 2008, as well as different types of blockchain. There are three types of blockchain: public (Bitcoin, etc.), federated or consortium (i.e., Maersk/IBM), and private (company internal). These types have similar concepts, but differ on their accessibility and validation methods. The first is permission-less; it does not have software requirements and uses a proof-of-work (PoW) consensus validation, while the other two are decentralized within their users (with network access restricted to the permitted users) and require a solution provider to develop the technology (i.e., Hyperledger, Azure, IBM, etc.) and an extra private key (password) to access the chain [28]. The second type, the federated/consortium blockchains, operates under the guidance of a group, which would have to confirm (sign) every block to confirm the transactions [28]. It is also based on the execution of smart contracts (the coding defining what is to happen if all of the parties agree) and allows the use of a "signature share", which combines a public and a private key to access a block. So, if someone discovers only one of the keys, the information will remain safe, as both keys are needed to access the block [29], as a solution to fight hacking attempts to maintain cybersafety. The third type is similar to the second, but strict to one company operation [28]. Other consensus algorithms have been developed and deployed to blockchains besides PoW; the most notable are the proof-of-stake, practical Byzantine fault tolerance, delegated proof-of-stake, Ripple, and the Tendermint [30].

Since blockchain was initially developed to serve Bitcoin, its first applications came within the finance industry. However, several companies have recently initiated projects implementing blockchain to other industries. Although many of these pioneering companies are small and medium-sized, some large corporations pay close attention to the development of this technology. One of them is IBM, which considers blockchain as a tool that will allow transactions between companies to simplify, facilitate interfirm collaboration, increase trust among partners, and decrease costs of transactions in many industries [27].

\section{Materials and Methods}

To answer this study's research questions, a case study methodology is applied. The Norwegian offshore industry was chosen as the case because of its well-known innovativeness. The population consisted of companies working in the Norwegian offshore industry, which applies to both Norwegian companies with operations in and/or outside of Norway, and foreign companies operating in Norway. A stratified sample of companies was selected based on three criteria: their presence in the offshore business, their interest and connection with innovation, and their use of technology in their operations. Two sub-cases were identified: the offshore operators and the offshore support players.

Both primary and secondary data was used in the study. The primary data consists of interviews, while the secondary data is derived from companies' reports, national and international media reports, company Web pages, and related publications. Seven semi-structured interviews-four with offshore operators and three with suppliers-were conducted by telephone and through Skype. The interview guide consisted of 15 open-ended and seven closed-ended questions. The interviewees were posed the questions in a funnel sequence, in which each successive question is related to the previous one in a progressively narrower scope [31]. A triangulation process was performed to ensure validity. The interview guide drew on different sources of information related to the companies' stakeholders 
as well as their utilization of blockchain and innovation: informed consent was obtained from all of the interviewees. While the actual names are not disclosed to preserve anonymity, the main characteristics of companies and informants are presented in Table 1. The interviews were recorded and then fully transcribed using the Trint software. The data was then processed, analyzed, and coded both deductively and inductively, using the NVivo software and a coding scheme. Fifteen deductive codes were derived from the theory and the interview guide. The inductive coding was especially useful here, in light of the sparse theory, and all 62 inductive codes were derived from the data. The codes were then processed further into drivers and barriers. The collected data shows similarities among the stakeholder groups, and such encountered patterns satisfy the consensus required by internal reliability.

The offshore maritime industry is engaged in operations supporting the extraction of marine resources (including offshore oil, gas, renewable energy, and minerals). The volume of offshore operations in the total of marine activities is constantly growing [4]. However, the oil and gas prices fell dramatically in 2014. Many offshore shipping companies had to decrease their operations; some companies went bankrupt. Facing these challenges, cutting costs and enhancing savings has become crucial for the offshore industry. Ward [32] has disclosed that the better use of existing technologies alone could provide up to USD 1 Billion in cost savings or production increase. Choudhry et al. [33] argued that maintenance costs can be reduced down to $13 \%$ when using advanced analytics for preventive maintenance, while Kendon [34] stated that the industrial use of the IoT could help prevent unplanned outages, hence allowing savings of up to USD 3 Million per week. In addition, digitally-enabled distributions and marketing can reduce costs down to $10 \%$ through optimized pricing models and supply chains [33]. Consequently, innovation has become a key differentiator in order to fulfill the demand and yet retain profits while overcoming the obstacles posed to the industry. With companies such as DNV GL, Kongsberg Maritime, as well as several start-ups, Norway has already established the presence of maritime and innovation development. 
Table 1. Profiles of the selected companies from the Norwegian offshore industry.

\begin{tabular}{|c|c|c|c|c|c|c|c|}
\hline Company & Sub-Case & $\begin{array}{c}\text { Year of } \\
\text { Establishment }\end{array}$ & $\begin{array}{l}\text { Number of } \\
\text { Employees }\end{array}$ & $\begin{array}{c}\text { Type of } \\
\text { Business/Specialization } \\
\end{array}$ & $\begin{array}{c}\text { Prior Blockchain } \\
\text { Experience }\end{array}$ & $\begin{array}{l}\text { Informants' Role in the } \\
\text { Company }\end{array}$ & Motive for Using Blockchain \\
\hline A & Operator & 1982 & 2200 & Offshore Exploration & No & $\begin{array}{l}\text { Manager Business Processes and } \\
\text { Systems }\end{array}$ & $\begin{array}{l}\text { Supply chain performance } \\
\text { improvement and cost reduction }\end{array}$ \\
\hline B & Operator & 1983 & 20 & Offshore Exploration & No & Purchaser & $\begin{array}{l}\text { Competitiveness by adapting to } \\
\text { bigger players }\end{array}$ \\
\hline C & Operator & 2005 & 4500 & Offshore Exploration & No & Technical Manager & $\begin{array}{l}\text { Supply chain performance } \\
\text { improvement and cost reduction }\end{array}$ \\
\hline $\mathrm{D}$ & Operator & 1995 & 1400 & Offshore Exploration & No & Technical Superintendent & $\begin{array}{l}\text { Supply chain performance } \\
\text { improvement and cost reduction }\end{array}$ \\
\hline E & Supporter & 1991 & 1715 & Offshore Seismic Research & No & Researcher & Source transparency and audits \\
\hline $\mathrm{F}$ & Supporter & 1965 & 74 & Offshore Installation & Yes & $\begin{array}{l}\text { Commercial and Technical Project } \\
\text { Manager }\end{array}$ & $\begin{array}{l}\text { Competitiveness by adapting to } \\
\text { big players }\end{array}$ \\
\hline G & Supporter & 1958 & 37,000 & Subsea/Offshore Solutions & Yes & Chief Technical Engineer & Cost reduction \\
\hline
\end{tabular}




\section{Results}

A three-dimension cluster analysis was performed based on Jaccard's coefficient to analyze the sources by coding similarity. The average Jaccard's coefficient for the analysis of all of the sources was equal to $84.9 \%$, indicating a high level of similarity. The key interviewee that reduced this level was Company B, and the differences related to answers mostly regarding technology. This may be because this was definitely the smallest company in our sample. No systematic differences were identified between the two sub-cases; the findings are therefore analyzed and presented as one main case. The most frequent topics of interest mentioned in the interviews were need (including ask, demand, involve, require, and want), which was mentioned 196 times in total-119 by operators and 77 by supporters - and cost (including cost-cutting, costly, price, prices, pricing), which was mentioned 137 times in total-96 times by operators, and 41 times by supporters.

\subsection{The Main Drivers of Digital Innovation}

All of the informants focused on cost as an important driver for innovation in general, both within their company and within the industry as a whole. As one of them claimed, "it's all about cost". The informants argued that "the cost is the main driver for the moment; the main driver and the main challenge to everything is located in the cost." Furthermore, one manager suggested:

"Resources and return on investment are 'very important' and when you invest in something, everybody is going to ask 'why'. So, as long as you can justify the investment, it's fine. The main thing now with this situation is if you can demonstrate that you will save money, [then] they might be ok with doing something."

Although company innovation is found to be really important in order to reduce prices and "fight the big dogs", the level of innovativeness seems to differ among companies. Overall, cost was identified as the most important driver for innovation for each company and within the industry. Shipping, is indeed an international business, with a significant number of international money transactions. Banks earn significant commission provisions on both international money transfers and currency exchange. The blockchain technology allows the fulfilling transactions without the help of the banking sector. It is impossible to counterfeit transactions in blockchain, since all of them are marked with a timestamp. This makes it possible to reduce a company's costs related to financial control and the auditing of subcontractors. Regulations represent another important driver, because when they change, they need to be followed, and the "classification society regulations make innovation happen faster". Different certificates that ensure that a company's processes comply with norms and regulations are issued. These certificates are easily forged, which can undermine the system. The usage of the blockchain technology could overcome this problem. A classification society creates a digital ID for each certificate, which is saved and can be accessed through blockchain. Shipping is also identified as an information-intensive industry. According to some informants, the amount of engineering documentation has increased tremendously. The utilization of blockchain allows the removal of the problem of document duplication and the duplication of quality control standards. The fourth and final driver is coded inductively as the wish to work more efficiently utilizing modern information technology opportunities. The industry is advanced with respect to technology, but projects and works are managed in a very conservative way, and are "not very modern". For example, regarding "the tools they use", and "there is a saying that the people working in the gas industry are cowboys". Using the blockchain technology allows making the product life cycle shorter. Customers can also track the state of services or goods that should be delivered in real time. Blockchain is "definitely much faster and it will reduce bureaucracy to get to our big data, and blockchain will further prove that". The informants argued that digitalization may be used to "streamline the organization, to make sure that everyone does the right things". Digitalization also helps "to be cost-effective, to have systems in the right place, as well as [be] less dependence on people". The informants also stated that onshore offices are "decades ahead" of offshore. Another comment is worth reporting in its entirety: 
"I'd like to see more innovation. I want to see more and more ways to work, and when you read the news or read about how other companies are working, and then you see the way you work, you think: 'OK, we're like 20 years behind.' Even though you have great success and get great projects done and you do very cool stuff. You do stuff 3000 meters underwater, and all kinds of things subsea. But when you do everyday work in a very old-fashioned way ... It's difficult."

To sum up, the main drivers of digital innovation within the maritime industry seem to be: (1) the possibility of saving costs; (2) strict regulations; (3) the information intensity in the industry; and (4) the desire to work more efficiently utilizing modern information technology opportunities.

\subsection{The Main Barriers of Digital Innovation}

Costs related to development, as well as the implementation and maintenance of digital systems, seem to be a barrier to digital innovation, because of the low-cost orientation of this industry. Some informants argued that:

"The actual cost lies in the training, the competency, the change of systems, etc. ( ... ).

The total cost of this is ( ... ) (related) to the benefit that it brings to the organization, and this will change the actual organizational outcome in the next two or five years."

One informant pointed out that "blockchain could help operations for sure, but may be too expensive. [It] could apply to enhance operations, but would need more studies to prove its efficiency". Therefore, the low-cost focus seems to be an important barrier to digital innovation within this industry.

Several informants stated that they have a challenge with low internet speed offshore, and denoted slow internet as "the limiting factor". Therefore, limited and slow internet speed is yet another barrier to digital innovation within this industry. It was also argued that perhaps "the suppliers don't use it. So, the whole supply chain has to use it to be successful". A current barrier therefore seems to be the low level of digital diffusion within the supply chain.

Furthermore, the informants argued that the industry has low risk-taking willingness as well as a long-term perspective on revenue for invested money. They do what they have to do, and "need something that is proven". One informant claimed that "the new technology does not have to be fully developed, but needs to be already in place somewhere else in the industry". Some informants claimed that they "rely much more on big data [which is] coming with high speed", while others are "following the big companies". Some willingness to invest in digitalization was identified, "but without being pioneers". The informants argued that it is "very early on the information technology (IT) innovation front" and that "the company is willing to take risks if benefit is there". It was also pointed out that the industry in general does not invest much in R\&D. Hence, another barrier seems to be some unwillingness to take risks and to be in the forefront within this industry.

The informants also agreed that this is quite a conservative and old-fashioned industry that works slowly. One reason is the identified reluctance to invest in the offshore industry: "The main challenge is that after this downturn in the industry, with the low oil price ... even though now [it] is going higher, going back on, the investors, the oil companies are very reluctant to invest again". The second reason addresses the industry culture by claiming that "in this conservative business, things take a long time", because we are "not pioneers". Furthermore, the informants claimed that the industry seems to follow others "if it's proven that it's a good solution". A third reason is that the decision-makers are still thinking in an old-fashioned way. However, the informants believe that in the future, the "younger generation will [much more quickly] understand the potential" of digitalization and "will see this more clearly". Therefore, the reluctance to invest, the old-fashioned non-pioneering culture, and conservative, senior decision-makers all represent barriers to digital innovation within this industry.

Finally, the findings also unveiled that the industry in general has a high focus on the engineering and installation technology, combined with a low focus on "how to carry out more efficient business processes". The industry is "interested in new technology", which is deemed "essential", and "willing 
to spend money on newer and more developed equipment, than just buy old stuff". However, the informants claimed also that the IT technology "is quite outdated" ... "on one side, you have resistance from the people that have been there for a very long time, reluctance to try something new". At the same time, you also have "the resistance from the IT department, for example, because ( ... ) to implement something new, you have to stand up to some 4000 people or $30,40,000$ people. So, it's quite a big change for them to do something". Even if most of the informants believed in digitalization and argued that this industry needs more and faster innovation in general in order to not "be out", one supplier also argued that the needed innovation "is more into technology". Therefore, the engineering and installation technology-oriented culture with a low focus on efficient business processes seems to be a barrier to digital innovation.

To sum up, (1) the low-cost focus; (2) the current limited and slow internet speed; (3) the current low level of digital diffusion within the supply chain; (4) the current reluctance to invest and a certain disinclination to risk-taking; (5) the reluctance to innovation leadership; (6) the old-fashioned, non-pioneering culture and conservative senior decision-makers; and (7) the engineering and installation technology-oriented culture with a low focus on efficient business processes all appear to be barriers to digital innovation within the maritime offshore industry.

\subsection{Relevant Areas from Implementing Blockchain Technology}

The empirical findings unveiled several areas for blockchain applications. It may encourage the information and management systems to work more efficiently and to reduce bureaucracy, by for instance implementing project management systems and providing more streamlined and online information. The informants argue that the industry is "actually quite bad in terms of data, documentation, and control processes". Furthermore, "payment probably would be good to track. We also might track documentation ... equipment should be tracked ... I really believe that it's a good opportunity to innovate and go forward". Blockchain application might also work well for contracts:

"To make sure that all the offices and the different companies communicate in the common way. I think that will help when we do the monthly reports for the projects. These guys spend like three days working nonstop- $12 \mathrm{~h}, 14 \mathrm{~h}$ a day-just to make sure everything adds up with its projects, so it's not very straightforward."

One informant pointed out that "if you have a good database of good software and a good system, that actually makes the processes running in a much better way, then it's definitely a good advantage for the industry". Corruption is a risk, albeit one that is not recognized by all as a major problem; however, "in some countries definitely yes. It is a challenge for them to say no, meaning that they might lose against the one who says yes and doesn't care." However, one supporter is "extremely afraid of it, of course. We don't want to be involved in any corruption scandal or whatsoever, so the top management here is focusing a lot on it." Therefore, there seems to be a great potential in organizing people, projects, payment, information, and communication in smarter and more efficient ways, and developing better and safer documentation and control systems. The industry might also have a potential in reducing the risk of corruption.

Regarding regulations and audits:

"There are requirements, so you are not coming away (from) this clause and internal audits and, all this stuff. (... ). It is something which is already built into the cost and it's done easily, it's not anything that obstructs the flow, no."

Audits are an ongoing required operation that the operators seem to have organized well as a "part of the normal business", with related costs being "no longer too high". Therefore, the informants do not see a great potential in the digitalization of audits.

The informants also focus on the importance of making the right strategic choices regarding "what type of innovation" to go for. Several see "more possibilities in software technology", and believe that "the benefit for the industry can lie more in smaller things". 


\section{Discussion}

There are several opportunities within the industry for digital innovation. Martinotti et al. [35] measured the impact of automation opportunities in the upstream industry (oil and gas exploring), and found that the majority of high-impact opportunities are in the later stages of development and production, and are separated throughout the chain. The data collected in this study supports the idea that the greatest opportunity for blockchain application lies in secure connected steps in order to optimize the chain as a whole and create value from it. This finding is also corroborated by IBM's Institute for Business Value Analysis [2].

In this study, we found out that several areas of the maritime industry may benefit from implementing blockchain. Blockchain has a great potential in organizing people and operations, such as projects, payments, information, and communication in smarter and more efficient ways, and in developing better and safer documentation and control systems. The industry might also have the potential to reduce the risk of corruption. On the other hand, the informants did not see a significant potential in the digitalization of audits. The informants also highlighted the importance of making the right strategic choices regarding the right type of innovation to follow. Several informants "see more possibilities in software technology", and "think that the benefit for the industry can be more in smaller things".

Not all of the innovations provided the right fit for the whole industry, as not everything that might solve one company's problems or challenges will do the same for all of the others. Further research is necessary to analyze each part of the industry in depth and separately, in order to connect to new possibilities: the company's size, goals, vision, financial capacity, and its interests regarding the specific innovation in analysis.

At the same time, the supply chain is undergoing a revolution. The IoT should connect devices to suppliers, anticipating demands and creating useful data from it. Blockchain's applicability to this architecture allows companies to keep an encrypted, immutable ledger of transactions, which can be trustfully shared within the selected network due to the peer-to-peer proof-of-work concept, eliminating the third parties involved, and thus saving money through reducing costs. This integration also supports applying collected data to follow the state of assets in real time, such as vessel parts that require changing or maintenance. However, it is important to highlight that blockchain does not replace database software or data analysis tools. More importantly, it does not replace transactional processing systems, although it can transform them [27].

The blockchain process framework (Figure 1) is developed to generate a basic operation's blueprint proposal with a "fingerprint" that cannot be altered. 


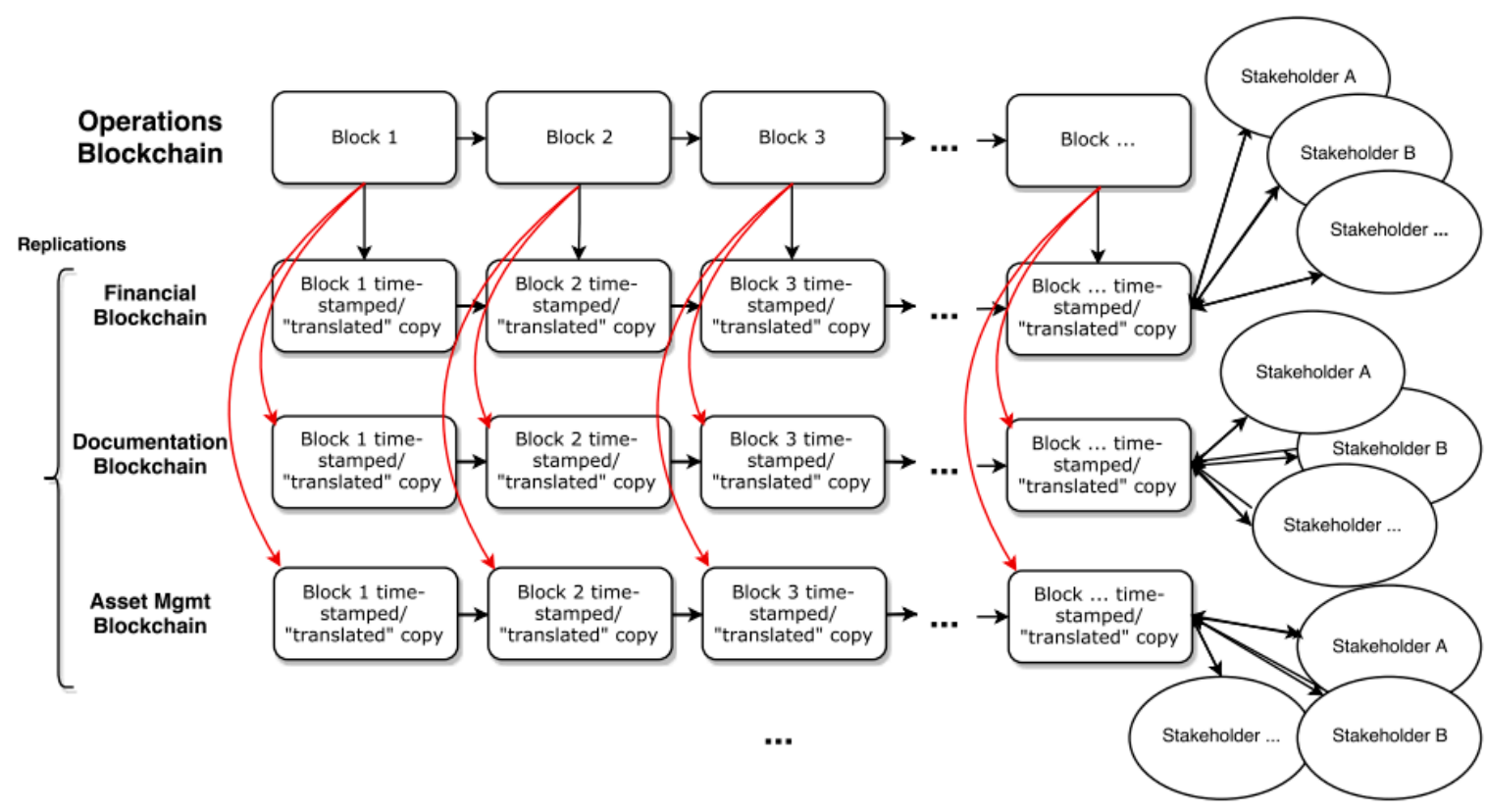

Figure 1. The Blockchain Process Framework (Source: the authors).

This framework proposes several basic chain pipelines, and is flexible to adapt to several different applications while following the same concept. The operation steps would generate a block with a hash, connecting into one main blockchain, which would have time stamped copies in real time. However, its content would be "translated" to other types of information related to the operations, such as financial information, asset management data, documentation, and certification for audits, vendors, and customers, and other possible pipelines. These would work based on the double-booking accounting system, only in this case with several record entries, as a third, a fourth and so on, pertinent to each block. Only the required stakeholders would then gain permission to access the relevant blockchain. Thus, the information would be protected while making it accessible to the parties that need it, and controlled by the company in charge. Since this theoretical concept is still not applied in practice, it does not have a measuring model. Future studies may develop measures and deploy the framework on an open-source code platform. Then, a more complex structure can be developed and applied in case studies with a relative lower cost than creating coding from scratch. This model may still require extra technology, such as for instance to enable the information "translation" from the main ledger to its replications, which also requires further research. Ideally, it would then connect to other technologies, such as the IoT for asset management, data for digital twins and artificial intelligence learning, and others. This will contribute to the creation of a sustainable supply chain.

Four drivers of digital innovation were identified in the empirical data. The industry's increased cost focus, which was highlighted in the literature review, was identified in the findings as the most important driver of digital innovation, due to the possibility of cost-saving. The extremely regulated feature of the maritime industry that was revealed in the literature review emerged in the findings as the second most important driver of innovation. Furthermore, regulations seem to speed up the innovation process, which was not mentioned in the literature. The third driver is the information-intensive feature of the industry, which was commented upon in the literature review. This driver was to some degree also identified in the findings. The fourth and final driver, which was denoted as "the intention to work more efficiently utilizing modern information technology opportunities", was not identified in the literature. Hence, the empirical findings represent a novel contribution to the literature. This driver might also be propelled by this industry being highly innovative regarding engineering and installation technology. 
Altogether, six barriers of digital innovation were identified in the empirical data. The low-cost focus in the industry was paradoxically also identified in the findings as an important barrier to digital innovation and blockchain. It is a barrier because of a short-term perspective of the costs related to the development and implementation of blockchain and other forms of digitalization, and because of the expected high costs of the development, implementation, and maintenance of digital systems. Furthermore, because of the benefits of digital innovation and blockchain might in many cases be difficult to estimate and remain uncertain, while the costs are closer and very tangible. In this case, shipping companies can cooperate and jointly develop new applications of blockchain for the shipping industry, i.e., using the coopetition approach [36]. Coopetition allows sharing risks and costs for R\&D works among competitors $[37,38]$. The second barrier is that access to the internet is currently limited offshore, and the speed is slow.

The third barrier is related to the diffusion of innovation [18]. The diffusion and the adoption rate of blockchain and digital innovation within the maritime industry in general, and the supply chain in particular, currently seems to be low on both the global and the national level. Moreover, it is localized to a few large companies and some start-ups. Such a lack of developed systems and software, as well as scarce knowledge related to benefits and opportunities, constitute a barrier. Moreover, the existence of business partners in the chain who do not make use of this technology reduces opportunities for digital chain communication. Another consequence of this finding, which was not identified in the literature, is related to company size. Small and medium-sized enterprises (SMEs) in general seem to be latecomers with respect to blockchain and digitalization within this industry.

The fourth barrier that was deduced from the findings was the current reluctance to investment and certain disinclination to risk-taking and innovation leadership. We argue that this barrier exists partly due to the long-term effects of the serious drop in oil prices, and the quite recent downsizing of the industry. However, we also envisage that this is related to the great technological distance between the old organization methods and the new digital way: according to Koc and Bozdag [39], an underestimation of this distance may cause problems in the allocation of resources and in the decision-making regarding investments. As to the reluctance of being in the forefront, we think this industry may be characterized as a "late majority" or even as "laggards", using Roger's [18] typology. Laggards, which are the latest typology to adopt innovation, are characterized by traditional values, by the past as their point of reference, and by a rational or irrational resistance to innovations [17].

The fifth barrier is related to the senior age of conservative decision-makers. This barrier may be reconducted to the laggard typology, and because young adults are generally found to be more creative and innovative than older adults $[40,41]$.

The sixth barrier is the old fashioned, non-pioneering, engineering and technology-oriented culture, with a low focus on efficient business processes. According to Rogers [18], the adoption rate is closely linked to values, beliefs, and past experiences, as well as influenced by how the characteristics of the innovation are perceived, and how complex such an innovation is. We argue that a technology-oriented culture and the high level of complexity of this type of innovation will contribute to keeping the adoption rate low.

The technical distance between the current old-fashioned IT and business systems, and the significant novelty of blockchain results in the low priority of the allocation of resources [39], and, the adoption rate is therefore kept low. Thus, companies in the maritime industry may be late adopters who are typologized as laggards of digitalization. Due to the vast technological distance and complexity, adopting a blockchain may be seen as a "paradigm innovation", and in order to allow such radical changes, a great cultural change is needed $[4,13]$. Our findings reveal that this great cultural change still has not happened in the explored companies. Within this context, blockchain seems to be a real challenge compared to digital innovation in general, as blockchain is really new, and is still to some extent experimental technology. Moreover, we have detected a paradox in our findings, i.e., that the industry culture in the Norwegian maritime sector is highly innovative in terms of engineering and technology; however, in terms of digital innovation, the firms in the industry are 
innovative laggards. We suggest that this paradox may be somewhat rooted in the engineering and technically-oriented core competence and culture. Table 2 summarizes the discussion of drivers and barriers to digital innovation in the maritime industry.

Table 2. Summary of the discussion of drivers and barriers to digital innovation. SMEs: small and medium-sized enterprises.

\begin{tabular}{|c|c|c|c|}
\hline Factor/Code & Driver & Barrier & Consistency Findings-Literature \\
\hline Cost & $X$ & $X$ & Consistent \\
\hline High level of regulation of the industry & $x$ & & $\begin{array}{l}\text { Consistent, but the findings added show that this factor } \\
\text { also speeds up the innovation process }\end{array}$ \\
\hline $\begin{array}{l}\text { The information-intensive feature of the } \\
\text { industry }\end{array}$ & $x$ & & $\begin{array}{l}\text { Identified in both places, but more emphasized in the } \\
\text { literature rather than in the findings }\end{array}$ \\
\hline $\begin{array}{l}\text { Intention to work more efficiently using } \\
\text { modern information technology opportunities }\end{array}$ & $x$ & & Not previously identified in the literature \\
\hline Limited and slow Internet speed offshore & & $x$ & Not previously identified in the literature \\
\hline $\begin{array}{l}\text { Low level of digital diffusion within the } \\
\text { supply chain }\end{array}$ & & $x$ & $\begin{array}{l}\text { Reduced benefit because other companies in the chain are } \\
\text { not using it; a lack of developed systems and software; } \\
\text { deficiency of knowledge related to benefits and } \\
\text { opportunities. Some large companies and start-ups are } \\
\text { early adopters, and SMEs in general seem to be latecomers, } \\
\text { which was not identified in the literature. }\end{array}$ \\
\hline $\begin{array}{l}\text { Reluctance to investment, risk-taking, and } \\
\text { innovative leadership }\end{array}$ & & $x$ & $\begin{array}{l}\text { First part is consistent, last part-reluctance innovation } \\
\text { leadership-is more emphasized in the findings }\end{array}$ \\
\hline $\begin{array}{l}\text { Old fashioned, non-pioneering culture and } \\
\text { conservative old-aged decision makers }\end{array}$ & & $x$ & Consistent, very clear findings \\
\hline $\begin{array}{l}\text { Old fashioned, non-pioneering, engineering } \\
\text { and technology-oriented culture with a low } \\
\text { focus on efficient business processes }\end{array}$ & & $x$ & $\begin{array}{l}\text { Not explicitly identified in the literature on SMEs in this } \\
\text { industry before }\end{array}$ \\
\hline
\end{tabular}

The timing for offshore seems right for innovation, in particular for Norway, which is a major player in the offshore industry, being traditionally a maritime nation. Since Norway is a high-cost country [42], it needs to invest in high value-added sectors and it needs to create a value from its knowledge. The government's assistance towards research and development is the key to allow and foster innovations in the field.

This study has got some limitations. Although the number of informants of the empirical study is relatively low, several secondary data sources are used in the literature review. The number of high-quality published academic papers on blockchain usability and challenges outside of bitcoin is insignificant. Finally, the newness of the technology is reflected in the rather scant benchmarking information, as very little is known about its application to the shipping and offshore industry. At the same time, it was precisely the scarcity of the existing information that prompted this research, and provided an opportunity to show something new to the industry. The blockchain process framework needs to be elaborated in further studies.

This study originated from the perception that the maritime industry lacks innovation in its operations and supply chain, being one of the late adopters with respect to new technology unrelated to drilling, productivity enhancement, or safety. The answer to the first research question is that financial, documentation, and asset management may benefit from applying Blockchain. To illustrate this point, the blockchain process framework has been developed in this study.

The answer to the second research question is that the possibility of reducing costs, along with the regulated and information-intensive feature of the industry, and the intention to work more efficiently by utilizing modern information technology opportunities, seems to represent the most important drivers of digital innovation within the maritime industry. Based on the literature review and the results, it is clear that the industry is motivated by costs and by the need of implementing something based on legal requirements. Just as in the case of the Port of Rotterdam, if required by the Port Authority, classification societies, the International Maritime Organization, or other similar bureaus, the industry rushes to adapt itself in an attempt to "future-proof" its assets, which could 
be a main catalyst of innovation and technological implementation. Furthermore, several barriers of digital innovation within the maritime industry emerged, such as development and implementations costs, limited and slow internet speed, a low level of digital diffusion within the supply chain, a reluctance to invest, a certain disinclination to risk-taking and being in the forefront, conservative and senior-aged decision makers, and the old-fashioned, non-pioneering, engineering and installation technology-oriented culture with a low focus on efficient business processes.

The answer to the third research question is that the areas of the maritime industry that may benefit from the implementation of blockchain are organizing people and operations such as projects, payments, information, and communication in smarter and more efficient ways, and developing better and safer documentation and control systems. Another area of blockchain application is the reduction of corruption risks. On the other hand, the informants do not see a great potential in the digitalization of audits. We also argue that the industry at present is suffering from a lack of knowledge regarding blockchain possibilities; that may very well change in the near future, based on the success of the pioneer's adoption.

Author Contributions: All authors contributed equally to the development of the paper. For the appropriate paper development, all stages have been discussed and worked out by the authors.

Funding: This research received no external funding.

Acknowledgments: The authors are thankful to the reviewers for providing valuable comments and suggestions. We also would like to thank two Guest Editors, Sroka and Cygler, for their general advice and support.

Conflicts of Interest: The authors declare no conflict of interest.

\section{References}

1. Nakamoto, S. Bitcoin: A Peer-to-Peer Electronic Cash System. 2008. Available online: http://bitcoin.me/ bitcoin.pdf (accessed on 4 January 2017).

2. IBM Institute for Business Value Analysis. Fast Forward: Rethinking Enterprises, Ecosystems and Economies with Blockchains; Executive Report; IBM Corporation: Armonk, NY, USA, 2016.

3. Yli-Huumo, J.; Ko, D.; Choi, S.; Park, S.; Smolander, K. Where is current research on blockchain technology? A systematic review. PLoS ONE 2016, 11, e0163477. [CrossRef] [PubMed]

4. Stopford, M. Maritime Economics, 3rd ed.; Routledge: London, UK, 2017.

5. Den Norske Veritas-DNV GL. Making Your Asset Smarter with the Digital Twin. 2016. Available online: https: / / www.dnvgl.com/article/making-your-asset-smarter-with-the-digital-twin-63328 (accessed on 5 July 2017).

6. Tien, J.M. Internet of connected ServGoods: Considerations, consequences and concerns. J. Syst. Sci. Syst. Eng. 2015, 24, 130-167. [CrossRef]

7. The Economist. The Data Deluge. 2010. Available online: https://www.economist.com/node/15579717 (accessed on 25 February 2010).

8. Van Doorn, E.; Friedland, R.; Jenisch, U.; Kronfeld-Goharani, U.; Lutter, S.; Ott, K.; Visbeck, M. World Ocean Review 2015: Living with the Oceans 4. Sustainable Use of Our Oceans-Making Ideas Work; Maribus GmbH: Hamburg, Germany, 2015.

9. DNV. Certificates in the Blockchain. 2018. Available online: https://www.dnvgl.com/assurance/certificatesin-the-blockchain.html (accessed on 3 February 2018).

10. Lacey, M.; Lisachuk, H.; Giannopoulos, A.; Ogura, A. Shipping Smarter: IoT Opportunities in Transport and Logistics; The Internet of Things in Shipping; Dupress-Deloitte: New York, NY, USA, 2015.

11. Solesvik, M. Innovation strategies in shipbuilding: The shipbuilding cycle perspective. Shipbuild. Mar. Inf. 2016, 5, 44-50. [CrossRef]

12. Polatidis, N.; Pavlidis, M.; Mouratidis, H. Cyber-attack path discovery in a dynamic supply chain maritime risk management system. In Computer Standards \& Interfaces; Elsevier: Oxford, UK, 2017.

13. Tidd, J.; Bessant, J.; Pavitt, K. Managing Innovation: Integrating Technological, Market and Organizational Change, 3rd ed.; Wiley \& Sons: New York, NY, USA, 2005.

14. Arlbjørn, J.S.; de Haas, H.; Munksgaard, K.B. Exploring supply chain innovation. Logist. Res. 2011, 3, 3-18. [CrossRef] 
15. Flint, D.J.; Larsson, E.; Gammelgaard, B.; Mentzer, J.T. Logistics innovation: A customer value oriented social process. J. Bus. Logist. 2005, 26, 113-147. [CrossRef]

16. Krabbe, M. Leverage supply chain innovation. Ind. Eng. 2007, 39, 26-30.

17. Deffeyes, K.S. Hubbert's Peak: The Impending World Oil Shortage; Princeton University Press: Princeton, NJ, USA, 2001.

18. Rogers, E. Diffusion of Innovations; The Free Press: New York, NY, USA, 1995.

19. Solesvik, M. Interfirm collaboration in the shipbuilding industry: The shipbuilding cycle perspective. Int. J. Bus. Syst. Res. 2011, 5, 388-405. [CrossRef]

20. Solesvik, M. Partner selection in green innovation projects. In Complex Systems: Solutions and Challenges in Economics, Management and Engineering; Berger-Vachon, C., Lafuente, A.M.G., Kacprzyk, J., Kondratenko, Y., Merigó, J.M., Morabito, C.F., Eds.; Springer: Cham, Switzerland, 2018; pp. 471-480.

21. Stevens, L.; Sys, C.; Vanelslander, T.; Hassel, E.V. Is new emission legislation stimulating the implementation of sustainable and energy-efficient maritime technologies? Res. Transp. Bus. Manag. 2015, 17, 14-25. [CrossRef]

22. Eniram. Starting Your Voyage towards the New World of Marine Digitalization; Eniram White Paper; Eniram: Helsinki, Finland, 2017.

23. Solesvik, M.; Kondratenko, Y.; Kondratenko, G.; Sidenko, I.; Kharchenko, V.; Boyarchuk, A. Fuzzy Decision Support Systems in Marine Practice. In Proceedings of the 2017 IEEE International Conference on Fuzzy Systems (FUZZ-IEEE), Naples, Italy, 9-12 July 2017; pp. 1-6.

24. Maersk. Maersk and IBM Target One of Trade's Biggest Barriers. 2017. Available online: https://www. maersk.com/stories/maersk-and-ibm-target-one-of-trades-biggest-barriers (accessed on 6 October 2017).

25. Lim, J. New opportunities for start-ups in the maritime sector. MPA's Smart Port Challenge. In Catalyses Maritime Industry towards Greater Innovation and Digitalisation; Corporate Communications Department, Maritime and Port Authority of Singapore (MPA): Singapore, 2017.

26. Elatab, M. Five Trends in Oil \& Gas Technology, and Why You Should Care. 2016. Available online: http: / /venturebeat.com/2012/03/28/5-trends-in-oil-gas-technologyand-why-you-should-care/ (accessed on 17 January 2018).

27. Gupta, M. Blockchain for Dummies; Wiley \& Sons: Hoboken, NJ, USA, 2017.

28. Blockchain Hub. Blockchains and Distributed Ledger Technologies. 2017. Available online: https://blockchainhub. net/blockchains-and-distributed-ledger-technologies-in-general/ (accessed on 15 September 2017).

29. Stathakopoulous, C.; Cachin, C. Threshold Signatures for Blockchain Systems; Swiss Federal Institute of Technology; IBM Research: Zurich, Switzerland, 2017.

30. Zheng, Z.; Xie, S.; Dai, H.; Chen, X.; Wang, H. An Overview of Blockchain Technology: Architecture, Consensus, and Future Trends. In Proceedings of the IEEE 6th International Congress on Big Data, Honolulu, HI, USA, 25-30 June 2017. Available online: https://www.researchgate.net/publication/318131748 (accessed on 7 March 2018).

31. Nachmias, D.; Nachmias, C.F. Research Methods in the Social Sciences, 7th ed.; Worth: New York, NY, USA, 2008.

32. Ward, R. A Billion-Dollar Digital Opportunity for Oil Companies. 2016. Available online: http:/ /www.mckinsey. $\mathrm{com} /$ industries/oil-and-gas/our-insights/a-billiondollar-digital-opportunity-for-oil-companies (accessed on 7 July 2017).

33. Choudhry, H.; Mohammad, A.; Tan, K.T.; Ward, R. The Next Frontier for Digital Technologies in Oil and Gas. 2016. Available online: http:/ /www.mckinsey.com/industries/oil-and-gas/our-insights/the-nextfrontier-for-digital-technologies-in-oiland-gas (accessed on 12 January 2018).

34. Kendon, P. Five Innovative Technologies Changing Maintenance Management in the Oil and Gas Sector. 2016. Available online: http://www.solufy.com/blog/5-innovativetechnologies-disrupt-maintenancemanagement (accessed on 12 January 2018).

35. Martinotti, S.; Nolten, J.; Steinsbø, J.A. Digitizing Oil and Gas Production. 2014. Available online: http:/ / www.mckinsey.com/industries/oil-and-gas/our-insights/digitizing-oil-and-gas-production (accessed on 7 October 2017).

36. Cygler, J.; Sroka, W. The boundaries of coopetition: A case study of Polish companies operating in the high-tech sector. In Economic Development and Entrepreneurship in Transition Economies; Ateljević, J., Trivić, J., Eds.; Springer: Cham, Switzerland, 2016; pp. 253-269. 
37. Cygler, J.; Sroka, W. Coopetition disadvantages: The case of the high tech companies. Eng. Econ. 2017, 28, 494-504. [CrossRef]

38. Solesvik, M. The Triple Helix model for regional development and innovation: Context of Nordic countries. Forum Sci. Oecon. 2017, 5, 5-21.

39. Koc, T.; Bozdag, E. Measuring the degree of novelty of innovation based on Porter's value chain approach. Eur. J. Oper. Res. 2017, 257, 559-567. [CrossRef]

40. Mumford, M.D.; Gustafson, S.B. Creativity syndrome: Integration, application, and innovation. Psychol. Bull. 1998, 103, 27-43. [CrossRef]

41. Scott, S.G.; Bruce, R.A. Determinants of innovative behavior: A path model of individual innovation in the workplace. Acad. Manag. J. 1994, 37, 580-607.

42. Norsk Industri. Norwegian Maritime Equipment Suppliers 2015-Key Performance Indicators and Future Expectations. 2015. Available online: http://www.menon.no/wp-content/uploads/28maritimeequipmentsuppliers_2015.pdf (accessed on 8 October 2017).

(C) 2018 by the authors. Licensee MDPI, Basel, Switzerland. This article is an open access article distributed under the terms and conditions of the Creative Commons Attribution (CC BY) license (http:/ / creativecommons.org/licenses/by/4.0/). 